\title{
MODEL PENINGKATAN IMPULSE BUYING MELALUI PHYSICAL SURROUNDING, SOCIAL SURROUNDING, DAN SALES PROMOTION
}

\author{
Siti Yuliana \\ Ken Sudarti \\ Universitas Islam Sultan Agung \\ Sitiyuliana161@gmail.com
}

\begin{abstract}
This study attempts to know whether physical surrounding, social surrounding, and sales promotion impact on impulse buying, exhibit visitors held in citraland mall .Population in this research is visitors exhibition. Samples to be taken as many as 100 respondents with using a technique explanory sample, using multiple regression technique. This research result indicates that physical surrounding have a positive influence to sales promotion. Social surrounding have a positive influence to sales promotion. Physical surrounding have a positive influence to impulse buying . Social surrounding have a positive influence to impulse buying. Sales promotion have a positive influence to impulse buying
\end{abstract}

Keywords : physical surrounding, social surrounding, sales promotion and impulse buying.

\section{PENDAHULUAN}

Dalam beberapa tahun terakhir usaha ritel mulai banyak di Semarang, mulai dari minimarket, supermarket hingga hypermarket. Hal ini juga di dukung oleh banyaknya jumlah penduduk Kota Semarang, karena dengan semakin banyaknya konsumen semakin banyak juga kebutuhan yang diperlukan, sehingga para pengusaha menganggap Semarang sebagai pasar yang potensial.

Tujuan utama ritel harus tercapai yaitu konsumen atau pengunjung ini melakukan pembelian. Pembelian dilakukan oleh konsumen tersebut bisa saja dilakukan secara spontan, tanpa pertimbangan yang rasional, dan konsumen merasa barang tersebut perlu dibeli. Harga yang diberlakukan, promosi dan suasana dalam ritel telah memainkan peranan penting dalam pembelian tak terencana yang di lakukan oleh konsumen (impulse buying).

Menurut Susanto (2007), sebagian besar konsumen Indonesia memiliki karakter unplanned. Mereka biasanya suka bertindak "last minute". Impulse buying adalah suatu kondisi yang dinamakan "unplanned purchase" atau pembelian yang tidak direncanakan yang kurang lebih adalah pembelian yang terjadi ternyata diluar perencanaan pembelian seorang konsumen. Salah satu factor yang mempengaruhi impulse buying adalah physical surrounding.

Physical surrounding adalah fitur suatu situasi yang paling mudah terlihat. Fitur ini mencakup lokasi geografis dan institusi, dekorasi, suara, aroma, penerangan, cuaca, dan suasana atau bentuk yang tampak dari barang atau material lain di sekitar obyek stimuli. Dan penelitian yang dilakukan oleh Park dan Lennon (2006) menunjukkan bahwa kuantitas dari interaksi antara pelanggan dan pelayan toko di dalam toko mempengaruhi pembelian impulse, penelitian ini sesuai dengan penelitian yang dilakukan Gutierrez (2002) yang 
menunjukkan bahwa lingkungan toko dan pelayan toko di dalam toko ritel mampu mempengaruhi pembelian impulse. Selain itu factor yang mempengaruhi adalah social surrounding.

Social surrounding adalah Lingkungan sosial melibatkan kehadiran orang lain, karakteristik orang-orang yang hadir pada situasi tersebut, peranan nyata orang-orang yang hadir, interaksi interpersonal, serta pengaruh dari orang lain atau individu yang hadir selama proses konsumsi terhadap aktifitas konsumen. Keberhasilan suatu perusahaan di pengaruhi oleh keahlian dari sales sehingga keefektifisien sales seuatu perusahaan mempengaruhi perusahaan itu sendiri.

Sales promotion adalah merupakan salah satu penentu keberhasilan suatu program pemasaran. Promosi penjualan pada hakikatnya adalah semua kegiatan yang dimaksudkan untuk menyampaikan atau mengkomunikasikan suatu produk atau jasa kepada pasar sasaran untuk segera melakukan suatu tindakan.

Berdasarkan penelitian-penelitian terdahulu beberapa faktor yang menjadi alasan mengapa seseorang terdorong untuk melakukan impulse buying diantaranya adalah karena faktor internal dan faktor eksternal. Faktor internal yang ada pada diri seseorang yaitu pada suasana hati dan kebiasaan mereka berbelanja apakah di dorong sifat hedonis atau tidak. Dan faktor eksternal yang mempengaruhi impulse buying yaitu pada lingkungan toko dan promosi yang ditawarkan oleh toko.

Selama libur panjang Mal Ciputra Semarang dipadati pengunjung bukan cuma dari pada tapi pula luar kota Semarang. Menurut PR Mal Ciputra Semarang, Aisa R Jusmar, ada peningkatan jumlah pengunjung sekitar 10\% $-15 \%$ selama libur panjang. "jikalau hari biasa sekitar 35000-4000 orang, akhir minggu panjang yaitu jumlah pengunjung mencapai 45.000-47.000 orang. Jumlah tersebut pula meningkat sebesar $10 \%$ dibandingkan dengan pengunjung yg datang dengan periode yg sama tahun lantas," Sumber: (Fista Novianti, Anggun Puspita / CN38 / SM Network)

\section{KAJIAN PUSTAKA \\ Physical Surrounding}

Physical surrounding adalah segala sesuatu yang berbentuk fisik di sekililing konsumen. Yang termasuk lingkungan fisik adalah beragam produk, toko, lokasi toko, dan lain-lain. Contoh: rumah adalah lingkungan mikro fisik dari konsumen, karena akan mempengaruhi sikap dan perilaku secara langsung (sumarwan, 2003). Physical surrounding merupakan sarana fisik yang menggambarkan situasi konsumen yang meliputi: dekorasi, aroma, cahaya, cuaca dan objek fisik lainnya yang berada di sekitar konsumen. Physical surrounding bisa meningkatkan sales promotion dengan cara memperindah bentuk fisik toko seperti memberikan variasi misalnya spanduk/ banner sebagai sarana promosi.

Lingkungan fisik (Physical Surrounding) yaitu aspek-aspek lingkungan fisik dan ruang yang nyata yang mencangkup aktivitas konsumen seperti warna, suara, cahaya, cuaca dan pengaturan ruangan. (Belk dalam Sutisna, 2001)

Lingkungan fisik (physical surroundings) adalah fitur suatu situasi yang paling mudahterlihat. Fitur ini mencakup lokasi geografis dan institusi, dekorasi, suara, aroma, penerangan, cuaca, dan suasana atau bentuk yang tampak dari barang atau material lain di sekitar obyek stimuli. (Dunne dan Lusch, 2008) menefinisikan lingkungan toko sebagai gambaran suasana toko yang tersusun dari beberapa elemen yang tersusun dari beberapa elemen, seperti music, pencahayaan, bentuk toko. petunjuk yang mengarahkan pengunjung serta elemen sumber daya manusia.

Indikator physical surroundings menurut David Yoon Kin tong, Kim Piew Lai, Xue La Tong (2012) adalah: pusat perbelanjaan yang mengesankan, ruangnya nyaman/wangi, tokonya besar, ada hiburanya seperti music. 


\section{Social Surrounding}

Lingkungan sosial (Social Surrounding) yaitu pengaruh orang lain terhadap aktivitas konsumen, individu yang hadir selama proses konsumsi, yang meliputi faktor-faktor seperti: kehadiran orang lain, karakteristik orang-orang yang hadir pada situasi tersebut, peranan nyata orang-orang yang hadir, dan interaksi interpersonal. (Belk dalam Sutisna, 2001)

Lingkungan sosial (Social Surrounding) secara luas didefinisikian sebagai semua interaksi sosial antara orang-orang. Hawkins et al. (2007) mengemukakan bahwa lingkungan sosial adalah kehairan orang lain dalam situasi tertentu. Tindakan konsumen seringkali dipengaruhi oleh apa yang ada di sekitar mereka. Perspektif waktu adalah karateristik situasional yang berhubungan dengan pengaruh waktu terhadap perilaku konsumen

Lingkungan sosial (social surrounding) memnerikan tambahan yang mendalam terhadap gambaran suatu situasi.

Indikator lingkungan sosial (pengruh teman/ keluarga, komentar dari seseoraang, kebanyakan masyarakat menggunakan barang apa, pengaruh sosial), David Yoon Kin tong, Kim Piew Lai, Xue La Tong (2012).

\section{Sales Promotion}

Promosi penjualan adalah kegiatan yang bertindak sebagai ajakan memberikan nilai tambah atau insentif untuk membeli produk, kepada para pengecer, penjualan atau konsumen. Sedangkan menurut menurut Lovelock dan Wirtz ( 2004 ) Sales promotion for service firms may take such forms as samples, coupons and other discounts, gift,sign-up rebates, and prize promotions. Sampel disini adalah upaya konsumen merasakan produk atau jasa secara gratis dengan harga miring. Kupon adalah sebuah sertifikat dengan nilai tertulis tertentu yang ditunjukkan kepada toko pengecer guna mendapatkan pengurangan harga produk tertentu selama periode waktu tertentu. Hadiah merupakan barang yang ditawarkan gratis atau dengan harga miring sebagai insentif karena membeli suatu produk. Kotler dan Armstrong (2006) mengemukakan bahwa promosi penjualan merupakan short-term insentif untuk mendorong konsumen agar melakukan pemebelian terhadap sebuah produk atau jasa. Insentif ini berkaitan dengan imbalan, apakah itu berkaitan dengan pengambilan uang dalam bentuk diskon, jaminan atau dapat berupa sample produk dan sebagainya. Kotler (2007) mengemukakan bahwa Indikator Sales Promotion terdiri dari: Customer promotion: sampel, kupon, rebates, priceoff, premium, contest, dan demonstrasi. Trade promotion-buying allowance: free goods, cooperative advertising, push money. Sales force promotion: pemberian bonus dan contest

\section{Impulse Buying}

MenurutRookdanFisher(Marketing2007) impulse buying sebagai kecenderungan konsumen untuk membeli secara spontan, reflek, tiba-tiba dan otomotis. Dari definisi ini terlihat terlihat bahwa impulse buying merupakan sesuatu yang alamiah dan merupakan reaksi cepat. Impulse buying terjadi pada saat konsumen masuk ke toko ritel dan ternyata membeli produk ritel itu tanpa merencanakan sebelumnya.

Dalam kegiatan impulse buying terbagi beberapa bentuk menurut Stern (Majalah Marketing, 2007) Reminder impulse buying yakni terjadi pada saat konsumen di toko, melihat produk dan kemudian membuatnya mengingat sesuatu akan produk tersebut. Bisa jadi dia ingat iklannya atau rekomendasi orang. impulse buying terjadi ketika konsumen benar-benar tidak merencanakan apapun untuk membeli. Suggested impulse buying dimana si pembelanja diperkenalkan produk tersebut melalui in store promotion. Planned impulse buying, dimana konsumen sebenarnya mempunyai rencana namun keputusan membelinya tergantung pada harga dan merek di toko tersebut. Berdasarkan uraian 
di atas, maka dapat di katakan bahwa impulse uying itu adalah suatu kegiatan yang didassarkan pada emosi seseorang yang timbul karena rsa ketertarikan pada produk tertentu. Ini di lakukan secara cepat tanpa berfikir panjang terlebih dahulu. Emosi ini terlibat karena adnya tuntunan untuk memenuhi kebutuhan hodup secara cepat. Beberapa indikator respon pelanggan yang digunakan dalam penelitian ini adalah sebagai berikut: Perasaan senang saat membeli secara spontan, Tidak mempertimbangkan konsekuensi, Membeli tanpa rencana

\section{Pengaruh Physical Surrounding Terhaadap Impulse Buying}

Donovan and Rossiter (1982) dalam Rohman (2009) juga mengungkapkan bahwa lingkungan fisik yang menyenangkan dapat mempengaruhi konsumen untuk membelanjakan uang yang dimiliki di luar yang direncanakan. Hal ini dapat diartikan bahwa lingkungan fisik dapat menimbulkan reaksi impulsive konsumen yang mendorong terjadinya keputusan pembelian impulsif.

Dalam penelitian yang dilakukan Gutieerez (2004) atribut supermarket mempengaruhi kegiatan impulse buying. Hal ini terjadi apabila adanya penataan barang dan kelengkapan barang yang disajikan. Kelengkapan ini biasanya disertai katalog yang berguna bagi konsumen yang akan membeli. Selain itu adanya kejelasan penempatan barang dalam melakukan kegiatan pembelian. Ini menandakan bahwa terjadinya impulse buying karena adanya kategori produk atau atribut produk atribut supermarket mengacu pada semua karakteristik fisik dan sosial konsumen, termasuk objek fisik (produk dan toko), hubungan ruang (lokasi toko dan produk dalam toko), dan perilaku sosial dari orang lain (siapa saja yang di sekitar dan apa saja yang mereka lakukan).

Penelitian yang dilakukan oleh Broekemier et al. (2008) menemukan bahwa lingkungan toko berpengaruh secara signifikan terhadap konsumen saat berbelanja, seperti adanya alunan musik di dalam toko yang menyebabkan konsumen menjadi lebih tertarik, serta niat belanja konsumen akan menjadi semakin tinggi ketika mendengar musik yang mereka sukai di dalam toko. Hasil penelitian tersebut mendukung penelitian yang dilakukan oleh Matilla and Wirtz (2008) yang menemukan bahwa lingkungan toko berpengaruh positif dalam merangsang minat konsumen serta meningkatkan pembelian yang tidak direncanakan oleh konsumen.

$\mathrm{H} 1$ : Physical surrounding berpengaruh positif terhadap impulse buying

\section{Pengaruh Social Surrounding Terhadap Impulse Buying}

Dalam penelitian Mattila dan Wirtz (2008), yang dimaksud faktor sosial yaitu konsumen lain dan karyawan toko, dan mengemukakan bahwa faktor sosial mempengaruhi pembelian impulsif. Berdasarkan hasil analisis yang dilakukan oleh Sinaga, dkk., (2010), diketahui faktor sosial berpengaruh positif dan signifikan terhadap pembelian impulsif.

Dalam penelitian Mattila dan Wirtz (2008), yang dimaksud faktor sosial yaitu konsumen lain dan karyawan toko, dan mengemukakan bahwa faktor sosial mempengaruhi pembelian impulsive.

Beberapa hal mengenai faktor situasional, seperti tingkat keramaian dan peran karyawan merupakan dimensi dari faktor sosial toko yang memiliki kecenderungan untuk mempengaruhi konsumen dalam melakukan pembelian tak terencana (Hetharie, 2012). Faktor lain yang juga memicu adanya pembelian tak terencana adalah faktor situasional. Rohman (2009) menyatakan faktor situasional merupakan suatu kejadian yang relatif pendek, dimana faktor tersebut akan mempengaruhi kegiatan dari konsumen, seperti pengaruh kebudayaan dan kepribadian konsumen.

$\mathrm{H} 2$ : Social surrounding berpengaruh positif terhadap impulse buying 


\section{Gambar 2.7 Kerangka Empirik}

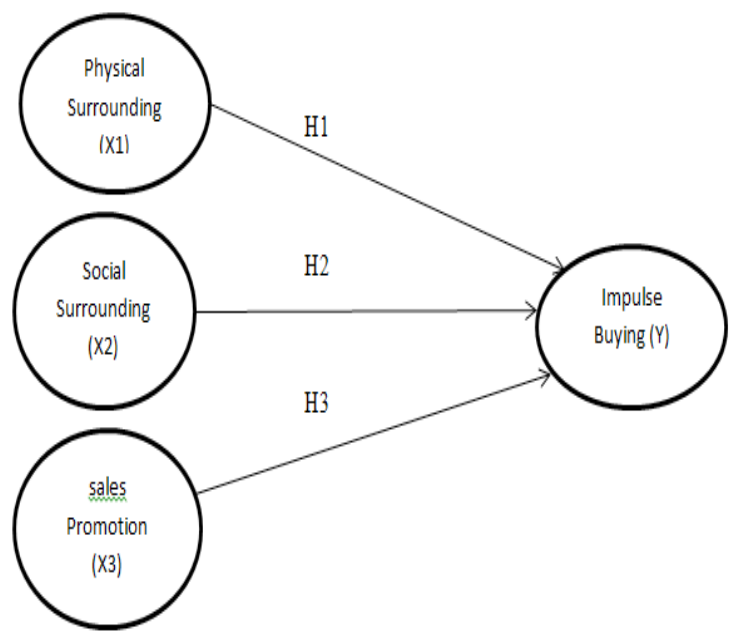

\section{Pengaruh Sales Promotion Terhadap Impulse Buying}

Menurut Boyd, Walker dan Larreche (2000), promosi penjualan (sales promotion) adalah kegiatan-kegiatan pemasaran selain penjualan pribadi, periklanan, dan publisitas, yang mendorong pembelian konsumen dan efektivitas penyalur. Promosi penjualan biasanya menawarkan insentif bagi konsumen dan penjual ulang untuk mendorong permintaan jangka pendek terhadap produk.

Hasil studi Weerathunga dan Phatmini (2015) menejelaskan bahwa sales promotion memiliki hubungan signifikan dengan impulse buying yang artinya semakin baik sales promotion makan semakin tinggi impulse buyingnya. Mullins et al (2005) mengatakan salah satu tujuan dari promosi penjualan adalah menciptakan ketertarikan dan mengalihkan perhatian dari harga. Intinya ketertarikan itu akan menimbulkan gairah atau antusiasme pembeli untuk membeli suatu produk dan tetap membeli kepada toko yang bersangkutan. Mengalihkan perhatian dari harga berkaitan dengan adanya perang harga diantaranya variasi harga, promosi kolektor harga, dan membuat perbandingan harga yang tidak langsung. Promosi terhadap nilai yang menciptakan ketertarikan dan mengakibatkan pembelian tidak terencana (impulse buying)

\section{METODEI PENELITIAN}

\section{Populasi dan Sampel}

Populasi yang ditetapkan dalam penelitian ini adalah pengunjung pameran yang diselenggarakan di mall citraland semarang yang telah melaksanakan pembelian dan jumlah populasinya ini tidak diketahui. Karena keterbatasan waktu penelitian maka penelitian dilakukan secara sampling. bahwa populasi yang ada sangat besar jumlahnya sehingga tidak mungkin untuk meneliti seluruh populasi yang ada. Dari perhitungan dapat diketahui sampel yang digunakan sebanyak 100 responden. Pengambilan sampel dilakukan dengan menggunakan metode accidental Sampling.

Perhitungan besarnya sampel ditentukan dengan menggunakan rumus sebagai berikut :

$$
\frac{Z^{2}}{4(M o e)^{2}}
$$

$\mathrm{n} \quad$ : jumlah sampel

Z : tingkat signifikansi

Moe: Margin error maksimum, yaitu tingkat kesalahan maksimum yang masih dapat diterima.

Maka jumlah sampel dalam penelitian ini dengan tingkat keyakinan 95\% diperoleh 
nilai $Z=1,96$ (tabel distribusi normal) dan tingkat kesalahan maksimum (Moe) $\pm 10 \%$ adalah sebagai berikut :

$$
\begin{aligned}
& n=\frac{(1,96)^{2}}{4(1,96)^{2}}=\frac{3,8416}{0,04}=96,04= \\
& 96 \text { responden }
\end{aligned}
$$

Atas dasar perhitungan diatas, maka sampel minimal yang digunakan adalah 96 orang. Untuk memudahkan penelitian dan memperoleh pengolahan data maka peneliti mengambil sebanyak 100 .

\section{Metode Pengumpulan Data}

Pengumpulan data yang digunakan untuk mengungkap data pengunjung mall ciraland semarang. Peneliti menggunakan metode pengumpulan data dengan observasi dan penyebaran kuesioner.

\section{Uji Validitas}

Uji validitas digunakan untuk mengetahui apakah masing-masing variabel dalam penelitian ini telah benar-benar sah atau tidak valid tidaknya suatu kuesioner. Jika $r$ hitung lebih besar dari $r$ tabel maka instrumen tersebut di katakan valid (Imam Ghozali, 2005).

\begin{tabular}{|c|c|c|c|c|}
\hline $\begin{array}{l}\text { Vanabel } \\
\text { Penelitian }\end{array}$ & Indikator & Nilair $r$ & Itabde $5 \%$ & Ket \\
\hline \multirow{2}{*}{$\begin{array}{l}\text { Physical } \\
\text { Sunounding }(X 1)\end{array}$} & $\begin{array}{l}\text { 1. Pusat berbelanja yang } \\
\text { mengesankan }\end{array}$ & 0,613 & 0,195 & Valid \\
\hline & $\begin{array}{l}\text { 2. Pencahayaan } \\
\text { 3. Nyaman }\end{array}$ & $\begin{array}{l}0,643 \\
0,714\end{array}$ & $\begin{array}{l}0,195 \\
0,195\end{array}$ & $\begin{array}{l}\text { Valid } \\
\text { Valid }\end{array}$ \\
\hline \multirow{4}{*}{$\begin{array}{l}\text { Social } \\
\text { Surrounding }(X 2)\end{array}$} & 1. Penganuh teman Keluarga & 0,624 & 0,195 & Valid \\
\hline & 2. Komentar dari seseorang & 0,675 & 0,195 & Valid \\
\hline & 3. Pengarnh social media & 0,513 & 0,195 & Valid \\
\hline & 1. Pemberian Kupon & 0,493 & 0,195 & Valid \\
\hline \multirow{2}{*}{$\begin{array}{l}\text { Sales Promotion } \\
\text { (X3) }\end{array}$} & 2. Pemberian Bonus & 0,561 & $0: 195$ & Valid \\
\hline & 3. Demonstasi yang menarik & 0,530 & 0,195 & Valid \\
\hline \multirow{3}{*}{$\begin{array}{l}\text { Impulse Buying } \\
\text { (Y1) }\end{array}$} & 1. Membeli secara spontan & 0,633 & 0,195 & Valid \\
\hline & $\begin{array}{l}\text { 2. Tidak memperitungan } \\
\text { konsskuensi }\end{array}$ & 0,669 & 0,195 & Valid \\
\hline & 3. Membell tanpa rencana & 0,546 & 0,195 & $\begin{array}{l}\text { Valid } \\
\text { Valid }\end{array}$ \\
\hline
\end{tabular}

Tabel 4.9

\section{Uji Reliabilitas}

Cara menghitung tingkat reliabilitas suatu data yaitu dengan menggunakan Alpha Cronbach. Suatu pertanyaan dikatakan reliabel jika pertanyaan tersebut dapat memberikan hasil yang tepat. Suatu pertanyaan dikatakan reliabel apabila memiliki $\alpha>0.6$ (Ghozali, 2013).

Tabel 4.10

Rekapitulasi Uji Reliabilitas

\begin{tabular}{llll}
\hline Variabel & $\begin{array}{l}\text { Koefisien } \\
\text { Cronbach Alpha }\end{array}$ & Alpha & Ket \\
\hline Physical Surrounding (X1) & 0,807 & 0,6 & Reliabel \\
Social Surrounding (X2) & 0,769 & 0,6 & Reliabel \\
Sales Promotion (X3) & 0,700 & 0,6 & Reliabel \\
Impulse Buying (Y1) & 0,775 & 0,6 & Reliabel \\
\hline
\end{tabular}

Sumber: data primer yang diolah, 2017

\section{Hasil Uji Regresi Linear Berganda}

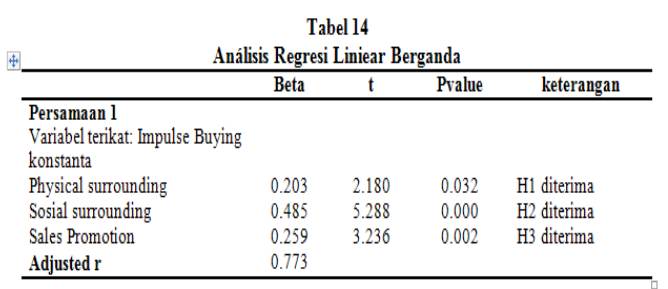

$$
Y_{1}=0,203 X 1+0,485 X 2+0,259 \times 3
$$

Hasil persamaan regresi berganda tersebut di atas memberikan pengertian bahwa :

Nilai koefisien regresi $X_{1}$ bernilai positif sebesar 0,203, mempunyai arti bahwa jika physical surrounding semakin meningkat, maka impulse buying akan meningkat.

Nilai koefisien regresi $X_{2}$ bernilai positif sebesar 0,485, mempunyai arti bahwa jika social surrounding meningkat, maka impulse buying akan meningkat.

Nilai koefisien regresi $\mathrm{X} 3$ bernilai positif sebesar 0,259, mempunyai arti bahwa sales promotion meningkat, maka impulse buying akan meningkat. 


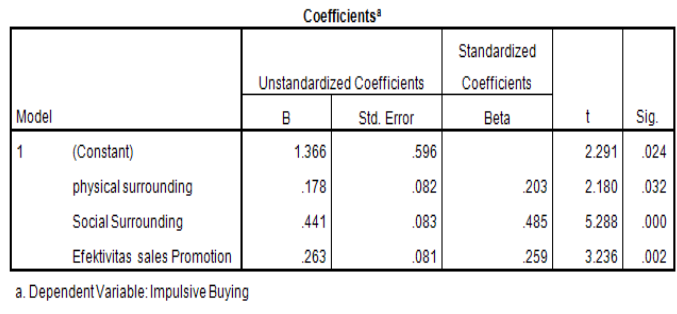

HASIL DAN PEMBAHASAN

Pengaruh Physical Surrounding terhadap Impulse Buying.

Dari hasil pengujian hipotesis diperoleh nilai t hitung Physical Surrounding sebesar 2,180 dengan nilai signifikan $0,032<0,005$, artinya physical surrounding berpengaruh positif terhadap impulse buying, yaitu suasana perbelanjaan yang nyaman, penataan produk yang menarik dan tata letak di setiap pameran yang mengesankan, maka impulse buying, yaitu membeli secara spontan, tidak memperhitungkan konsekuensi, membeli tanpa rencana.

Physical surrounding berperan penting dalam menarik minat konsumen, selain itu pembeli juga menyukai stimulus toko yang dapat menimbulkan nilai positif bagi konsumen sehingga meningkatkan pembelian tidak terencana.

\section{Pengaruh Social Surrounding terhadap Impulse Buying}

Dari hasil pengujian hipotesis diperoleh nilai $t$ hitung Social Surrounding sebesar 5,288 dengan signifikan $0,000<0,005$, artinya social surrounding berpengaruh positif terhadap impulse buying, yaitu banyaknya kerumunan disekitar pameran sangat mempengaruhi keputusan berbelanja, komentar orang-orang disekitar pameran sangat mempengaruhi keputusan berbelanja, banyaknya orangorang di social media memposting berita pameran sangat mempengaruhikeputusan berbelanja, impulse buying yaitu membeli secara spontan, tidak memperhitungkan konsekuensi, membeli tanpa rencana.

\section{Pengaruh Sales Promotion terhadap Impulse Buying}

Dari hasil pengujian hipotesis diperoleh nilai $\mathrm{t}$ hitung Efektivitas Sales Promotion sebesar 3,236 dengan signifikan 0,002 < 0,005 , artinya efektivitas sales promotion berpengaruh positif terhadap impulse buying, yaitu demonstrasi dari sales promotion saat pameran menarik, kupon yang diberikan sangat menarik, membeli dipameran karena diskonnya besar, impulse buying yaitu membeli secara spontan, tidak memperhitungkan konsekuensi, membeli tanpa rencana.

\section{SIMPULAN}

Berdasarkan penelitian yang telah dilakukan dengan menyebarkan angket kepada konsumen Citraland Mall Semarang khususnya pengunjung pameran, maka kesimpulan dari penelitian ini adalah Physical surrounding mempunyai pengaruh positif terhadap impulse buying. Artinya suasana perbelanjaan yang nyaman, penataan produk yang menarik dan tata letak di setiap pameran yang mengesankan, maka impulse buying, yaitu membeli secara spontan, tidak memperhitungkan konsekuensi, membeli tanpa rencana. Social surrounding mempunyai pengaruh positif terhadap impulse buying. Artinya banyaknya kerumunan disekitar pameran sangat mempengaruhi keputusan berbelanja, komentar orang-orang disekitar pameran sangat mempengaruhi keputusan berbelanja, banyaknya orangorang di social media memposting berita pameran sangat mempengaruhikeputusan berbelanja, impulse buying yaitu membeli secara spontan, tidak memperhitungkan konsekuensi, membeli tanpa rencana. sales promotion mempunyai pengaruh positif terhadap impulse buying. Artinya demonstrasi dari sales promotion saat pameran menarik, kupon yang diberikan sangat menarik, membeli dipameran karena diskonnya besar, impulse buying yaitu membeli secara spontan, tidak 
memperhitungkan konsekuensi, membeli tanpa rencana.

Dari hasil tanggapan responden variabel physical surrounding rata-rata jawaban responden yang terendah ada di indikator penataan produk pameran menarik. Saran yang diberikan sebaiknya pemilik pameran membuat display produk semenarik mungkin dan perhatikan pencahyaannya agar produk terlihat mencolok, golongkan produk sesuai jenisnya agar mempermudah konsumen saat belanja.

Dari hasil tanggapan responden variabel social surrounding rata-rata jawaban responden yang terndah ada di indikator komentar di sekitar pameran. Agar pemilik pameran dapat komentar positif maka buat stan pameran dengan dekorasi yang unik untuk menarik minat pengunjung, selain itu presentasikan produk dengan baik dan menggunakan pengeras suara agar mudah didengar pengunjung. Dengan cara seperti ini komentar positif didapatkan dari pengunjung

Dari hasil tanggapan responden variabel sales promotion rata-rata jawaban responden yang terendah ada di indikator kupon saat pameran menarik. Sebaiknya pemilik pameran memberikan kupon belanja kepada konsumen dengan nominal tertentu, dengan adanya kupon membuat konsumen antusias dalam berbelanja. Dari hasil tanggapan responden impulse buying rata-rata jawaban responden yang terendah ada di indikator membeli secara spontan. Pemilik pameran hendaknya melakukan perencanaan toko, penyajian barangbarang, desain toko, dan komunikasi visual, sehingga terjadinya pemebelian yang spontan.

Keterbatasan dalam penelitian ini adalah variabel physical surrounding dapat menjelaskan physical surrounding sebesar $37,4 \%$, sedangkan sisanya $62,6 \%$, dijelaskan oleh variabel lain yang tidak diamati dalam penelitian ini, untuk itu penelitian selanjutnya bisa lebih menjelaskan physical surrounding dengan menambah variabel bebas, seperti suhu ruangan, dekorasi yang unik, dan lailain.

\section{DAFTAR PUSTAKA}

A. B. Susanto, A. B. (2007). Corporate Social Responsibility. The Jakarta Consulting Group. Jakarta.

Boyd, Walker, Larreche. (2000). Manajemen Pemasaran Suatu Pendekatan Strategis dengan Orientasi Global Edisi 2 Jilid 1. Jakarta: Erlangga.

Broekemier, Greg., Ray. M., and James W. G. (2008). An Exploration of Happy/Sad And Liked/ Disliked Music Effects On Shopping Intentions In A Woman's Clothing Store Service Setting. Journal of Services Marketing, 22 (1) : 59-67.

avid Yoon Kin Tong dan Kim Piew Lai. (2012). Ladies' purchase intention during retail shoes sales promotions. International Journal of Retail \& Distribution Management, 40 (2) : 90108.

Donovan, R.J. and Rossiter, J.R. (1982). Store Atmosphere: An Environment Psychology Approach. Journal of Retailing, 58 (Spring): 34-57.

Dunne, P \& Lusch, R. (2008). Retailing edition. Mason: Thomson Higher Education.

Ghozali, Imam, (2013). Aplikasi Analisis Multivariate dengan Program SPSS. Yogyakarta: Badan Penerbit BPFE.

Gutierrez, Ben Paul B. (2002). Planned Versus Impulse Buying: Implications To Retail Search Strategies." Discussion Paper No. 0205 
Gutierrez. Ben Paul. B. (2004). Determinants of Planned and Impulse Buying : The Case of the Philippines. Asia Pacific Management

Hawkins, D. I., Mothersbaugh, D. L., \& Best, R. J. (2007). Consumer Behavior:Building Marketing Strategy. New York: McGraw Hill Company Inc

Gutierrez. Ben Paul. B. (2004). Determinants of Planned and Impulse Buying : The Case of the Philippines. Asia Pacific Management

Kotler, Philip. and Keller K.L. (2007), "Manajemen Pemasaran Jilid. 2", Indonesia, Macanan Jaya Cemerlang, Edisi 12.

Lovelock,C and Wirtz,J. (2004). "Services Marketing", Fifth Edition, Prentice Hall, New Jersey

Matilla, Anna S and Jochen Wirtz. (2008). The Role of Store Environmental Stimulation And Social Factors On Impulse Purchasing. Journal of service marketing, 22 (7) : 562-567.

Mullins, John W., Orville C. Walker Jr., Jean Claude Larreche, and Harper W. Boyd. (2005). Marketing Management : a Strategic Decision Making approach, Fift Edition. Newyork : The mc graw - Hill companies.

Park, Fihye dan Sharron F. Lennon. (2006). Psychological and environmental antecedents of impulse buying tendency in the multichannel shopping context. Journal of Consumer Marketing, 23(2) : 58-6.

Rohman, Fatchur. (2009). Peran Nilai Hedonik Konsumsi dan Reaksi Impulsif Sebagai Mediasi Pengaruh Faktor Situasional Terhadap Keputusan Pembelian Impulsif di Butik Kota Malang.

Rook and Fisher Majalah Marketing. (2007). Impulse Buying : Tantangan Baru Pemilik Merek. Marketing : Jakarta

Sutisna. (2001). Perilaku konsumen \& komunikasi pemasaran (edisi ke-3). Bandung: Remaja Rosdakarya.

Sumarwan, Ujang. (2003). Perilaku Konsumen. Penerbit Ghalia Indonesia : Jakarta. 